\title{
Pediatric Emergence Delirium is Linked to Increased Early Postoperative Negative Behavior within Two Weeks After Adenotomy
}

\section{Houben $\mathrm{A}^{1 *}$, Ghamari $\mathrm{S}^{1}$, Fischer $\mathrm{A}^{2}$, Neumann $\mathrm{C}^{1}$, Baehner $\mathrm{T}^{3}$ and Ellerkmann RK ${ }^{1}$}

${ }^{1}$ Department of Anesthesiology and Operative Intensive Care Medicine, Klinikum Dortmund, Germany

${ }^{2}$ ASG GbR Anesthesia and Pain Therapy, Moenchengladbach, Germany

${ }^{3}$ St. Nikolaus-Stiftshospital, Andernach, Germany

\section{Research Article}

Volume 5 Issue 2

Received Date: May 26, 2020

Published Date: June 05, 2020

DOI: $10.23880 / \mathrm{accmj}-16000174$

*Corresponding author: Houben A, Department of Anesthesiology and Operative Intensive Care Medicine, Klinikum Dortmund gGmbH, Beurhausstrasse 40,44137 Dortmund, Germany, Tel: +49231 953 21391; Email: anne.houben@klinikumdo.de

\section{Abstract}

Background: The aim of this prospective multicenter observational study was to measure the incidence of postoperative pediatric emergence delirium (ED) and to investigate the occurrence of early postoperative negative behavior (ePONB) within two weeks after outpatient adenotomy in preschool children.

Methods: The study comprised $n=222$ patients between 1 and 7 years of age. Premedication was performed orally with Midazolam (0.3-0.5mg/kg). All children received a multimodal anesthesia based on total intravenous anesthesia with Propofol and Remifentanil in combination with preemptive Dipidolor [Piritramid] $(0.1 \mathrm{mg} / \mathrm{kg})$, Ibuprofen $(10 \mathrm{mg} / \mathrm{kg})$, Dexamethasone $(0.15 \mathrm{mg} / \mathrm{kg})$ and Ketanest $S(0.1 \mathrm{mg} / \mathrm{kg})$. Applyingintravenous Clonidin $(2 \mu \mathrm{g} / \mathrm{kg})$ intraoperatively was left to the discretion of the anesthesiologist. We evaluated ED and pain using the PAED-scale and the FLACC-score at different predefined time points during the recovery period. ED was defined as a PAED score $\geq 9$ for the first 3 criteria. Additionally, we defined ePONB to be present when at least 5 of 27 criteria of the questionnaire were positive.

Results: The incidence of postoperative delirium following our multimodal anesthetic approach was $25 \%$. The postoperative incidence of ePONB was significantly higher among patients with ED ( $24 \%$ vs. $11 \%, \mathrm{p}=0.04)$.

Conclusion: Despite the multimodal pharmacological approach, the incidence of ED after adenotomy remains high. ED not only plays a role immediately after surgery but is also linked to ePONB within two weeks after outpatient adenotomy. Parents should be informed that ePONB may occur in 1 out of 4 patients if ED was present postoperatively.

Keywords: Emergence delirium (ED); Early Postoperative Negative Behavior (ePONB); Pediatric; Multi-Modal Anesthesia; Adenotomy 


\section{Anaesthesia \& Critical Care Medicine Journal}

\section{Introduction}

Postoperative emergence delirium (ED) following anesthesia remains an unsolved problem [1,2]. Several risk factors have been identified for example pain [3] surgical procedures such as ear, nose, and throat surgery (ENT) $[4,5]$ and age $[5,6]$. In combination with certain anesthetic concepts, the incidence of ED can reach up to $80 \%[5,7]$. Nevertheless, several clinical studies have shown that opioids [8,9] total intravenous anesthesia (TIVA) [10], Ketamine [9], and Dexamethason [11] can reduce the risk of ED. Risk reduction (RR) for Sevofluran-anesthesia was measured as $37 \%$ for opioids (in particular fentanyl), $35 \%$ for Propofol, and $30 \%$ for Ketamine. However, to the best of our knowledge, no study has yet investigated the incidence of ED following a multimodal anesthetic concept combining Propofol, Ketamine, Dexamethason, and opioids after outpatient adenotomy for 1 to 7 year old children. We therefore aimed to prospectively perform a multicenter observational study in children investigating the incidence of ED following a multimodal anesthetic regime in elective outpatient adenotomy. Several scales and scores have been published previously to measure ED objectively. The PAEDScore, being the "gold standard" [12] in the past, has been recently adjusted by Locatelli et al. [13]. He modified the scale by focusing only on the first three criteria thus increasing the specificity of this scale. Locatelli disregarded criteria 4 and 5 for defining ED as they - more or less - describe agitation. In our present study we therefore defined ED as proposed by Locatelli.

As ED is an acute disorder that occurs immediately after recovery from anesthesia, it is unknown whether long term sequelsmayalso occurpostoperatively.Kainetal.described the incidence of ePONB (early postoperative negative behavior) after outpatient surgical interventions being as high as $50 \%$ [14]. Risk factors for ePONB were identified as increased anxiety of the child in the preoperative holding area [14-16]. Further risk factors linked to ePONB were identified such as child's age, number of siblings, and baseline temperament [14]. Summarized, the aim of this study was to investigate the incidence of postoperative emergence delirium and early postoperative negative behavior in patients following a multimodal anesthetic regime. We therefore performed prospectively a multicenter observational study in children undergoing elective outpatient adenotomy.

\section{Methods}

Following Ethics Committee approval (University Clinic Bonn, Germany) and parental written informed consent, we consecutively enrolled 222 (166 patients in Bonn, 56 patients in Moenchengladbach) children between 1 and 7 years of age scheduled for elective outpatient adenotomy with or without myringotomy. Exclusion criteria were ASA classification $\geq 3$, critical illness with hemodynamic instability, active bleeding or mental retardation. Premedication was performed orally with Midazolam $(0.3-0.5 \mathrm{mg} / \mathrm{kg}) 30$ to $60 \mathrm{~min}$ prior to induction of anesthesia. Anesthesia was preferably induced intravenously with Propofol $(2-4 \mathrm{mg} / \mathrm{kg})$ or alternatively via face mask with 4 to $8 \%$ Sevoflurane and $100 \%$ oxygen. Thereafter the anesthesia regime was switched to a TIVA (total intravenous anesthesia) and the airway was secured by a laryngeal mask. Standard monitoring included ECG, EtCO2, pulse oximetry and non-invasive blood pressure. After surgery was completed and spontaneous breathing restored, the laryngeal mask was removed and patients were subsequently transferred to the PACU to reunite with their parents. All children received a multimodal anesthesia based on TIVA (Propofol and Remifentanil), Piritramid $(0,1 \mathrm{mg} / \mathrm{kg})$, Ibuprofen $(10 \mathrm{mg} / \mathrm{kg})$, Dexamethason $(0,15$ $\mathrm{mg} / \mathrm{kg}$ ) and Ketanest $S(0,1 \mathrm{mg} / \mathrm{kg})$. Applying intravenous Clonidin $(2 \mu \mathrm{g} / \mathrm{kg})$ intraoperatively was left to the discretion of the anesthesiologist. After recovery from anesthesia the occurrence of ED (postoperative emergence delirium) was monitored by applying the PAED-Score (Pediatric Anasthesia Emergence Delirium-Score) (Table 1).

ED was defined according to Locatelli, et al. [13] as a so called ED I score of $\geq 9$ (0 to 12 possible points) for the first 3 criteria of the PAED-Score (eye contact, purposeful movement, aware of surrounding). We additionally evaluated pain in the PACU applying the FLACC-Score (Table 2) to differentiate between pain related agitation and postoperative delirium. Pain was defined as a FLACC score of $\geq 4$. Score guided assessment started right after awakening (Time 1) and was reevaluated after 20 minutes (Time 2) and prior to discharge from the PACU (Time 3). In addition, reevaluation was performed in case of obvious strange behavior, reawakening or after an intervention by the anesthesiologist following a previously diagnosed ED. 14 days postoperatively, patients' parents were interviewed (via phonecall) using a questionnaire for possible postoperative negative behavior (ePONB) (Table 3) that was handed out towards the parents before discharged home from the ambulatory. We defined ePONB to be present when at least $\geq 5$ of 27 questions of this questionnaire were answered positively. The questionnaire was published by Buehrer et al. [17] and is a German translation of the PHBQ (PostHospitalization Behavioral Questionnaire) questionnaire from Vernon, et al. [18] published in 1966. 


\section{Anaesthesia \& Critical Care Medicine Journal}

\begin{tabular}{|c|c|c|c|c|c|c|c|}
\hline & Criteria & The Child... & Not At All & Just A Little & Quite A Bit & Very Much & Extremely \\
\hline & 1 & keeps eye contact & 4 & 3 & 2 & 1 & 0 \\
\cline { 2 - 8 } & 2 & $\begin{array}{c}\text {.. shows purposefull } \\
\text { movements }\end{array}$ & 4 & 3 & 2 & 1 & 0 \\
\cline { 2 - 8 } $\begin{array}{c}\text { Delire } \\
\text { criteria(ED I } \\
\text { score) }\end{array}$ & 3 & $\begin{array}{c}\text {.. Is aware of } \\
\text { surrounding }\end{array}$ & 4 & 3 & 2 & 1 & 0 \\
\hline $\begin{array}{c}\text { Agitation } \\
\text { Criteria (ED II) } \\
\text { Score }\end{array}$ & 4 & ... is restless & 0 & 1 & 2 & 3 & 4 \\
\cline { 2 - 8 } & 5 & ...is inconsolable & 0 & 1 & 2 & 3 & 4 \\
\hline
\end{tabular}

Table 1: PAED (pediatric anesthesia emergence delirium) scale based on Delir-criteria (EDI) and Agitation-criteria (ED II) according to Locatelli et.al [13].

\begin{tabular}{|c|c|c|}
\hline Observation & Assessment & Points \\
\hline \multirow{3}{*}{ Cry } & No cry (awake or asleep) & 0 \\
\hline & Moans or whimpers, occasional complaint & 1 \\
\hline & Crying steadily, screams or sobs, frequent complaints & 2 \\
\hline \multirow{3}{*}{ Face } & No particular expression/Smiling & 0 \\
\hline & Occasional grimace or frown, withdrawn, uninterested & 1 \\
\hline & Frequent to constant quivering chin, clenched jaw & 2 \\
\hline \multirow{3}{*}{ Consolability } & Content, relaxed & 0 \\
\hline & Reassured by occaisonal touching, hugging or being talked to, distractible & 1 \\
\hline & Difficult to console or comfort & 2 \\
\hline \multirow{3}{*}{ Legs } & Normal position or relaxed & 0 \\
\hline & Uneasy, restless, tense & 1 \\
\hline & Kicking or legs drawn up & 2 \\
\hline \multirow{3}{*}{ Activity } & Lying quietly, normal position, moves easily & 0 \\
\hline & Squirming, shifting, back and forth, tense & 1 \\
\hline & Arched, rigid or jerking & 2 \\
\hline & Number of points & \\
\hline
\end{tabular}

Table 2: FLACC-Scale.

\begin{tabular}{|c|c|c|c|c|}
\hline \multirow{2}{*}{ Number } & \multicolumn{2}{|c|}{ Questions } & \multicolumn{2}{c|}{ Answers } \\
& \multicolumn{2}{|c|}{$\begin{array}{c}\text { less then } \\
\text { before }\end{array}$} & $\begin{array}{c}\text { same as } \\
\text { before }\end{array}$ & $\begin{array}{c}\text { more than } \\
\text { before }\end{array}$ \\
\hline 1 & \multicolumn{2}{|c|}{ Does your child make a fuss about going to bed at night? } & & \\
\hline 2 & \multicolumn{2}{|c|}{ Does your child make a fuss about eating? } & & \\
\hline 3 & Does your child spend time just sitting or lying and doing nothing? & & \\
\hline 4 & \multicolumn{2}{|c|}{ Does your child need a pacifer? } & & \\
\hline 5 & Does your child seem to be afraid of leaving the house with you? & & \\
\hline 6 & Is your child uninterested in what goes on around him (or her)? & & \\
\hline 7 & \multicolumn{2}{|c|}{ Does your child wet the bed at night? } & & \\
\hline 8 & Does your child bite his (or her) finger nails? & & & \\
\hline
\end{tabular}


Anaesthesia \& Critical Care Medicine Journal

\begin{tabular}{|c|c|c|c|c|}
\hline 9 & Does your child get upset when you leave him (c & r her) alone for & few minutes? & \\
\hline 10 & Does your child need a lot of help doing things? & & & \\
\hline 11 & \multicolumn{4}{|c|}{ Is it difficult to get your child interested in doing things (like playing games with toys)? } \\
\hline 12 & \multicolumn{2}{|c|}{ Does your child seem to be avoid or be afraid of new things? } & & \\
\hline 13 & \multicolumn{2}{|c|}{ Does your child have difficulty making up his (or her) mind? } & & \\
\hline 14 & Does your child have temper tantrums? & & & \\
\hline 15 & Is it difficult to get your child to talk to you? & & & \\
\hline 16 & \multicolumn{4}{|c|}{ Does your child seem to get upset when when someone mentions doctors or hospitals? } \\
\hline 17 & \multicolumn{2}{|c|}{ Does your child follow you everywhere around the house? } & & \\
\hline 18 & \multicolumn{2}{|c|}{ Does your child spend time trying to get or hold your attention? } & & \\
\hline 19 & Is your child afraid of the dark? & & & \\
\hline 20 & \multicolumn{2}{|c|}{ Does your child have bad dreams at night or wake up and cry? } & & \\
\hline 21 & \multicolumn{2}{|c|}{ Does your child have irregular bowel movements? } & & \\
\hline 22 & \multicolumn{2}{|c|}{ Does your child have trouble getting to sleep at night? } & & \\
\hline 23 & Does your child seem to be shy around strangers? & & & \\
\hline 24 & Does your child have a poor appetite? & & & \\
\hline 25 & Does your child tend to disobey you? & & & \\
\hline 26 & Does your child break toys or other objects? & & & \\
\hline 27 & Does your child suck his (or her) fingers or & thumbs? & & \\
\hline
\end{tabular}

Table 3: German version of the Post-Hospitalization Behavioral Questionnaire (PHBQ) by Buehrer et al. [17].

\section{Statistics}

Statistical analysis was performed using Microsoft Excel 2016. Further analysis was performed using Gnu Regression (gretl), Econometrics and Time-series Library 2016d (Allin Cottrell and Riccardo Lucchetti). Statistical significance was evaluated with Fisher exact Test. $\mathrm{P}<0.05$ was considered statistically significant.

\section{Results}

Written informed consent was given by 234 care-givers. Of these 234 patients 12 had to be discarded from further analysis due to the following reasons: 8 patients only received a myringotomy and 4 patients additionally received a tonsillectomy, resulting in 222 children being included in the study and completing final statistical analysis. Screening for ePONB two weeks after surgery was successful in 178 patients $(80.2 \%)$. Due to a false phone number $(n=9)$, unavailability despite several phone call attempts $(\mathrm{n}=23)$, and language barrier $(\mathrm{n}=12) 44$ patients in total $(19.8 \%)$ could not be interviewed two weeks after surgery. Demographic data between the two sites (Bonn and Moenchengladbach) were comparable [data not shown]. The incidence of ED in this observational study was $25 \%$. The occurrence of ePONB within the observed period of time (two weeks) was $14 \%$ ( $\mathrm{n}=25$ of 178 patients). ED was positively correlated with the occurrence of ePONB with an incidence of $24 \%$ in patients developing ED versus an incidence of only $11 \%$ for patients without ED, $p=0.04$, (Table 2). An increase of postoperative sleep duration of 15 min resulted in a reduction of ED of approximately $50 \%, \mathrm{p}=0,0002$ (Figure 1). Furthermore, age correlated with the incidence of ED (Figue 2). Older children had a lower risk for ED than younger children. Unexpectedly, the incidence of ED was significantly higher in male patients compared to female patients $(29 \%$ vs. $15 \%, \mathrm{p}=0.02)$. However, boys were significantly younger at the time point of surgery ( $3 \pm 1.2$ years) compared to girls $(4 \pm 1.6$ years) ( $p$ $<0,001$ ) (Table 3). Further analysis of ePONB revealed that postoperative negative behavioral changes mostly arose in the categories "sleep disturbance" and "separation anxiety" (Figure 5). When investigating the 27 items of the PHBQ questionnaire in all patients tested positive for ePONB we could reveal certain questions to be of a higher relevance than others. $84 \%$ of patients with ePONB answered positively on either of the two questions: "did you detect a higher incidence of nightmares in your child" or "did you detect more sleeping disturbances". $76 \%$ of positively tested patients answered that "their child became anxious when it was left alone for a few minutes". 
Anaesthesia \& Critical Care Medicine Journal

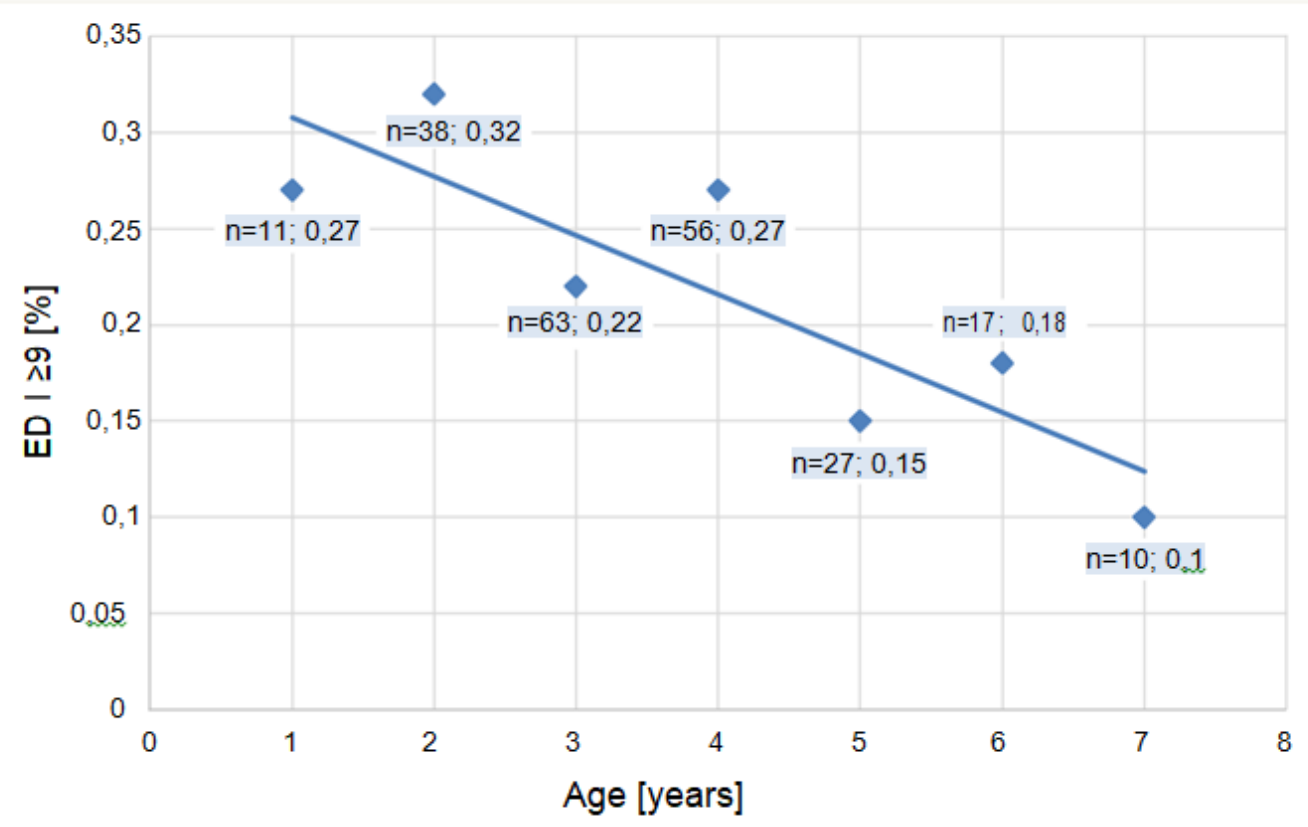

Figure 1: ED according to sleep duration at PACU.

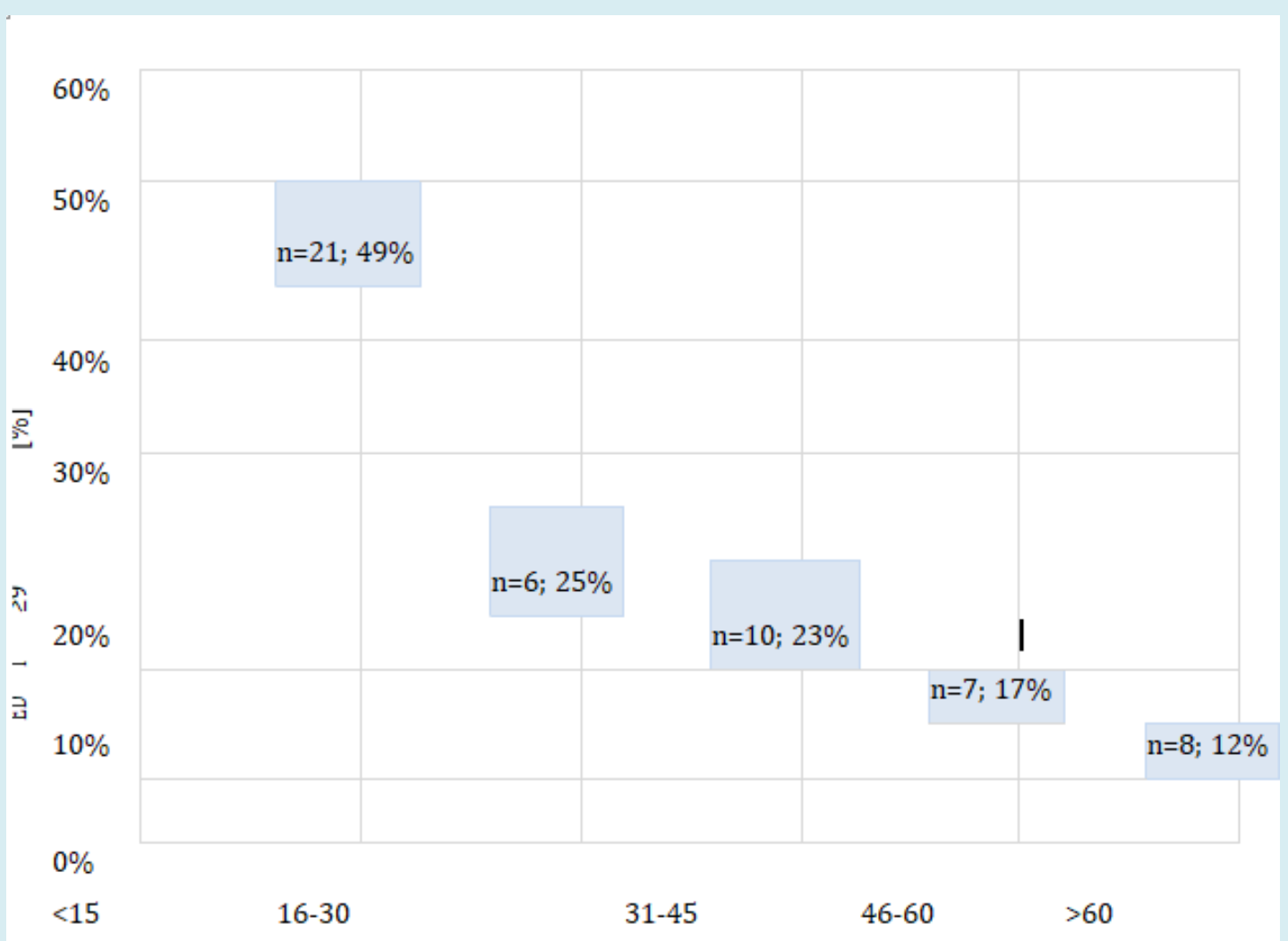

Figure 2: Prevalence of ED according to the patient's age. 


\section{Anaesthesia \& Critical Care Medicine Journal}

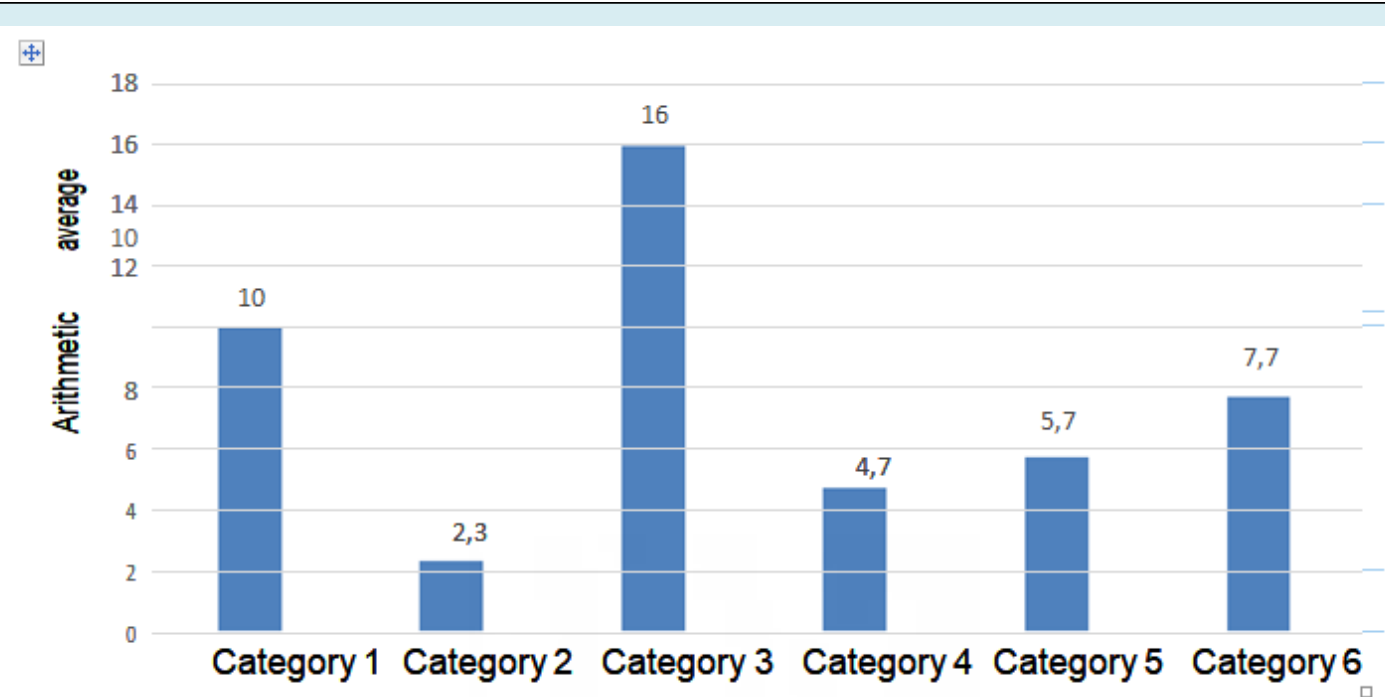

Figure 3: Arithmetic average of questions answered with "more than before" within particular categories; Category $1=$ separation anxiety; Category 2 = apathy; Category 3 = sleep disturbance; Category 4 = general anxiety and regression; Category 5 = withdrawal; Category 6 = eating disturbance

\begin{tabular}{|c|c|c|c|}
\hline & ePONB & no ePONB & total \\
\hline ED & 10 & 32 & 42 \\
\hline no ED & 15 & 121 & 136 \\
\hline total & 25 & 153 & 178 \\
\hline $\begin{array}{l}\text { Fisher's exact test: } \\
\text { p-Value: } 0,044867\end{array}$ & & & \\
\hline
\end{tabular}

Table 4: Correlation of ED (emergence delirium defined as ED I $\geq 9$ ) and ePONB (early postoperative negative behavior defined as $\geq 5$ of 27 criteria of the questionnaire being positive).

\begin{tabular}{|c|c|c|c|}
\hline & Male & Female & P-Value \\
\hline Age [years] & $3 \pm 1.21$ & $4 \pm 1.62$ & $<0.001$ \\
\hline ASA (I:II) & $96: 21$ & $74: 11$ & 0.436 \\
\hline Anesthesia Duration [min] & $37 \pm 14$ & $35 \pm 14$ & 0.36 \\
\hline Sleep Duration [min] & $50 \pm 32$ & $47 \pm 28$ & 0.43 \\
\hline ED I $\geq 9$ (Y:N) [\%] & $29: 71$ & $15: 18$ & 0.024 \\
\hline ED I (Time 1) & $4 \pm 4.27$ & $2 \pm 3.70$ & 0.04 \\
\hline ED I (Time 2) & $2 \pm 3.70$ & $1 \pm 2.86$ & 0.2 \\
\hline ED I (Time 3) & $1 \pm 2.20$ & $0 \pm 1.06$ & 0.27 \\
\hline FLACC (Time 1) & $2 \pm 2.60$ & $1 \pm 2.36$ & 0.5 \\
\hline FLACC (Time 2) & $1 \pm 2.53$ & $1 \pm 2.07$ & 0.12 \\
\hline FLACC (Time 3) & $0 \pm 1.37$ & $0 \pm 0.71$ & 0.25 \\
\hline FLACC Total & $1 \pm 2.30$ & $1 \pm 1.90$ & 0.17 \\
\hline Induction Quality (calm:restless) & $91: 37: 00$ & $67: 21: 00$ & 0.44 \\
\hline Induction Quality (calm:restless) [\%] & $71: 29: 00$ & $76: 24: 00$ & 0.44 \\
\hline
\end{tabular}

Table 5: Clinical data for male and female patients, data are given as mean \pm standard deviation. 


\section{Anaesthesia \& Critical Care Medicine Journal}

\section{Discussion}

Our investigation revealed a high incidence of ED of $25 \%$ following adenotomy in preschool children despite a multimodal anesthetic concept. Interestingly, ED seems to be linked to the incidence of ePONB within two weeks after outpatient adenotomy. Incidences of ED published in the literature alter significantly depending on risk factors such as age and type of surgery as well as the applied anesthetic concept. Pieters, et al. described an incidence of ED of 53\% [19]. The comparability of these two studies is difficult due to different definitions of ED ( $\geq 16$ points in all criteria of the PAED-Score vs. $\geq 9$ points for criteria 1-3 of the PAED-Score), different pain-Scores applied (CHEOPS vs. FLACC-Score) and different surgical interventions investigated (tonsillectomy vs. adenotomy). Despite these limitations that become apparent when comparing incidences of different studies, we believe that the "low" incidence of ED in our study may be attributed to the multimodal anesthetic concept. The highest incidence of ED published by Grundmann et al. after Desflurane anesthesia and "ENT" (e.g. adenotomy with bilateral myringotomy and insertion of tubes and/or tonsillectomy) surgery was $80 \%$. [7]. Chandler, et al. [20] could show that the mere change from a volatile anesthetic to a Propofol based anesthesia reduced ED by nearly $50 \%$ from an incidence of $38.3 \%$ to $14.9 \%$ after "strabismus surgery" [20].

The reported incidence of ED in our study is therefore in line with previously published data despite the discrepancy of comparing the underling methodological differences. Aono and colleagues have previously shown that preschool children reveal a higher incidence of ED after sevoflurane anesthesia compared to school children [6]. However, a difference in the incidence of ED between boys and girls has not been reported previously [21]. The higher incidence of ED in male patients in our study could not be explained by "higher excitement" levels during induction of anesthesia or higher FLACC scores after adenotomy (Table $3)$. On the other hand, we detected a significant difference in age between male and female patients. This difference in lower age may have contributed to the detected increased incidence of ED in boys. Early postoperative negative behavior (ePONB) was diagnosed applying the German version of the PHBQ questionnaire [17]. The questions were grouped in 6 categories: "separation anxiety", "apathy", "sleep disturbance”, "general anxiety and regression", "withdrawal", and "eating disturbance" [17]. Incidences of ePONB differ considerably within the published literature $[14,15,21]$. Comparing these incidences is difficult due to different definitions of ePONB. Kain, et al. defined ePONB as at least one positive answered question of the PHBQ [14] while Faulk, et al. [21] defined that at least seven questions must be answered positively. This might explain why the incidence reported by Faulk
$(8,8 \%)$ was lower compared to Kain's investigations (54\% and $78,4 \%$ ). In contrast to Kain, et al. reported incidences of ePONB within two weeks after outpatient surgery $[14,15]$ the incidence of ePONB for our patients was comparatively low with $14 \%$ (Table 2). It is tempting to speculate that this "lower" incidence of ePONB in our study may be attributed to the performed multimodal anesthetic concept resulting in a lower incidence of ED of $25 \%$. In fact, Kain, et al. previously described that the incidence of ED is correlated with the incidence of ePONB [15]. Our results of ED being positively correlated with ePONB $(24 \%$ vs. $11 \%, p=0.04)$ are therefore in line with Kain's finding. On the other hand, Faulk's published incidence of ePONB of 8,8\% [21] is lower compared to our measured incidence of $14 \%$. An explanation might be seen in the different definition of ePONB (7 positive idems [21] of the PHBQ questionnaire versus 5 items applied in our investigation). Furthermore, we believe that type of surgery (dental procedure versus adenomomy) and age ( 1 to 12 years versus 1 to 7 years) have an impact on the incidence of ePONB. It becomes evident that out of the six defined categories within the PHBQ „sleep disturbance“ and "separation anxiety" (Figure 3) were found to be the most frequent postoperative changes in our investigated patients. Kain et al. also described a higher prevalence of "separation anxiety", while "sleep disturbance" was not found to be one of the most common behavioral changes [14]. The difference may be explained by the fact, that the children in our study were younger. Furthermore, Kain, et al. used the PHBQ in the Version of Vernon [18] while we used the German Version of the PHBQ from Buehrer, et al. [17]. An essential difference between these two questionnaires is the different assignment of specific questions to the 6 mentioned categories. While Vernon's version assigns "having bad dreams or waking up at night crying" and "get upset when you leave him (or her) alone for a few minutes" to the category "separation anxiety", Buehrer's version assigns these questions to the category "sleep disturbance". When breaking down our results to single questions, our study was in line with Kains [14] results showing that the questions "having bad dreams or waking up at night crying" and "getting upset when left alone for a few minutes" were the most frequently positively answered questions.

\section{Conclusion}

Despite a multimodal pharmacological approach, the incidence of ED after outpatient adenotomy remained as high as $25 \%$ in our investigation. ED not only plays a role immediately after surgery but was linked to ePONB within two weeks after adenotomy. In summary, ED affects one of four preschool children following adenotomy and could not be prevented in all cases. Basically, it seems advisable to explain ED to parents ahead of surgery and inform on ePONB that may occur after discharge. 


\section{Anaesthesia \& Critical Care Medicine Journal}

\section{References}

1. Costi D, Cyna AM, Ahmed S, Stephens K, Strickland P, et al. (2014) Effects of sevoflurane versus other general anaesthesia on emergence agitation in children. Cochrane Database Syst Rev (9): CD007084.

2. Mason KP (2017) Paediatric emergence delirium: a comprehensive review and interpretation of the literature. Br J Anaesth 118(3): 335-343.

3. Bortone L, Bertolizio G, Engelhardt T, Frawley G, Somaini $M$, et al. (2014) The effect of fentanyl and clonidine on early postoperative negative behavior in children: a double-blind placebo controlled trial. Paediatr Anaesth 24(6): 614-619.

4. Swart ED, Rajah C, Rodseth RN (2017) Induction behaviour and race and its association with postoperative agitation in paediatric elektive surgery. South Afric J Anaesth and Analg 23(2): 36-39.

5. Voepel-Lewis T, Malviya S, Tait AR (2003) A prospective cohort study of emergence agitation in the pediatric postanesthesia care unit. Anesth Analg 96(6): 16251630.

6. Aono J, Ueda W, Mamiya K, Manabe M, Takimoto E (1997) Greater incidence of delirium during recovery from sevoflurane anesthesia in preschool boys. Anesthesiology 87(6): 1298-1300.

7. Grundmann U, Uth M, Eichner A, Wilhelm W, Larsen R (1998) Total intravenous anaesthesia with propofol and remifentanil in paediatric patients: a comparison with a desflurane- nitrous oxide inhalation anaesthesia. Acta Anaesthesiol Scand 42(7): 845-850.

8. Tan Y, Shi Y, Ding H, Kong X, Zhou H, et al. (2016) $\mu$-Opioid agonists for preventing emergence agitation under sevoflurane anesthesia in children: a meta-analysis of randomized controlled trials. Paediatr Anaesth 26(2): 139-150.

9. Dahmani S, Stany I, Brasher C, Lejeune C, Bruneau B, et al. (2010) Pharmacological prevention of sevoflurane- and desflurane-related emergence agitation in children: a meta-analysis of published studies. Br J Anaesth 104(2): 216-223.

10. Kanaya A, Kuratani N, Satoh D, Kurosawa S (2014) Lower incidence of emergence agitation in children after propofol anesthesia compared with sevoflurane: a metaanalysis of randomized controlled trials. J Anesth 28(1): 4-11.
11. Sajedi P, Baghery K, Hagibabie E, Mehr AM (2014) Prophylactic Use of Oral Acetaminophen or IV Dexamethasone and Combination of them on Prevention Emergence Agitation in Pediatric after Adenotonsillectomy. Int J Prev Med 5(6): 721-727.

12. Sikitch N, Lerman J (2004) Development and psychometric evaluation of the pediatric anesthesia emergence delirium scale. Anesthesiology 100(5): 11381145.

13. Locatelli BG, Ingelmo PM, Emre S, Meroni V, Minardi C, et al. (2013) Emergence delirium in children: a comparison of sevoflurane and desflurane anesthesia using the Paediatric Anesthesia Emergence Delirium scale. Paediatr Anaesth 23(4): 301-308.

14. Kain ZN, Mayes LC, O'Connor TZ, Cicchetti DV (1996) Preoperative anxiety in children. Predictors and outcomes. Arch Pediatr Adolesc Med 150(12): 12381245.

15. Kain ZN, Caldwell-Andrews AA, Maranets I, McClain B, Gaal D, et al. (2004) Preoperative anxiety and emergence delirium and postoperative maladaptive behaviors.

Anesth Analg 99(6): 1648-1654.

16. Kain ZN, Caldwell-Andrews AA, Mayes LC, Weinberg ME, Wang SM, et al. (2007) Family-centered preparation for surgery improves perioperative outcomes in children: a randomized controlled trial. Anesthesiology 106(1): 6574.

17. Buehrer S, Klaghofer R, Weiss M, Schmitz A (2015) Verhaltensauffälligkeiten von Kindern und Jugendlichen nach Narkose : Entwicklung einer deutschsprachigen Version des Post Hospitalization Behavior Questionnaire [Negative behavioral changes in children and adolescents after anesthesia : Development of a German language version of the Post Hospitalization Behavior Questionnaire]. Anaesthesist 64: 115-121.

18. Vennon DT, Schulman JL, Foley JM (1966) Changes in children's behavior after hospitalization. Some dimensions of response and their correlates. Am J Dis Child 111(6): 581-593.

19. Pieters BJ, Penn E, Nicklaus P, Bruegger D, Mehta B, et al. (2010) Emergence delirium and postoperative pain in children undergoing adenotonsillectomy: a comparison of propofol vs sevoflurane anesthesia. Paediatr Anaesth 20(10): 944-950.

20. Chandler JR, Myers D, Mehta D, Whyte E, Groberman MK, Montgomery CJ et al. (2013) Emergence delirium in children: a randomized trial to compare total 
Anaesthesia \& Critical Care Medicine Journal

intravenous anesthesia with propofol and remifentanil to inhalational sevoflurane anesthesia. Paediatr Anaesth 23(4): 309-315.
21. Faulk DJ, Twite MD, Zuk J, Pan Z, Wallen B, et al. (2010) Hypnotic depth and the incidence of emergence agitation and negative postoperative behavioral changes. Paediatr Anaesth 20(1): 72-81. 